\title{
Analysis of Changes in Total Factor Productivity for Academic Departments of Historically Privileged Small University in South Africa
}

\author{
Juniours Marire \\ Department of Economics and Economic History, Rhodes University, P. O. Box 94, Grahamstown, South \\ Africa, 6140 \\ * E-mail of the corresponding author: j.marire@ru.ac.za
}

\begin{abstract}
In an environment of rising levels of student debt and falling government financial support to universities, the problem of lack of financial sustainability is becoming endemic, especially among small universities. This calls for universities to identify new sources of income growth. Using a case study of a small historically privileged South African university, we examined the change in total factor productivity for the period 2004-2015. We adopted an intra-institutional departmental efficiency comparison using the Malmquist Total Factor Productivity Index under an output-oriented data envelopment analytic framework and assuming variable returns to scale. The index was decomposed into technical efficiency change, technical change, pure efficiency change, and scale efficiency change. We found that total factor productivity growth was driven by technical progress, scale efficiency improvements and to some extent technical efficiency improvements. Departments in the Faculty of Science mostly seem to have experienced greatest levels of technical change although they lagged the Department of Accounting. Because of the dominance of technical change in driving total factor productivity growth, an important source of income growth, our findings imply that universities should design institutional systems of innovation that can engender financial sustainability through increased innovation and total factor productivity growth.
\end{abstract}

Keywords: Total factor productivity, scale efficiency, technical change, technical efficiency, South Africa, historically privileged small university

DOI: $10.7176 / \mathrm{EJBM} / 12-18-02$

Publication date:June 30th 2020

\section{Introduction}

The study of economic efficiency of public institutions of higher learning has a long tradition in social thought. As early as the 1970 s scholars argued that the education sector was ripe for efficiency analysis because of "size and rising costs" (Levin, Jamison, \& Radner, 1976: 149) and gradually falling government financial support (Bok, 2003; Kao \& Hung, 2008; Marire, 2017; Mitchell, Leachman, \& Masterson, 2017; Moreno \& Tadepalli, 2002; Rayeni, Vardanyan \& Saljooghi, 2010). Globally, it is a stylized fact that the cost of higher education has been rising much faster than the general price level (Archibald \& Feldman, 2008; Baum, 2016; Calitz \& Fourie, 2016; Dumestre, 2016) and the advent of massification of higher education has resulted in bloated higher education institutions (Teixeira, 2009). Occasionally, massification has become a commercial strategy to earn large input subsidies from government for enrolling many students. Massification has not only been about increased numbers of students being enrolled for degrees, but also it has penetrated the peer reviewed publications field with many universities moving towards incentivizing research (Willmott, 2003). It is the age of an entrepreneurial academy (Hong \& Walsh, 2009).

In the wake of the global financial crisis and austerity policies that followed it, there has been a surge in studies elsewhere in the world, especially in developed countries, that sought to establish levels of efficiency and the ways through which knowledge of drivers of efficiency changes could potentially impact on financial sustainability of public universities (Dumestre, 2016; Hong \& Walsh, 2009; Mitchell, Palacios, \& Leachman, 2015). The level of analysis has been mostly pitched at the inter-university comparison level although some studies have attempted to carry out intra-university comparisons (Arcelus \& Coleman, 1997; Kao \& Hung, 2008; Moreno \& Tadepalli, 2002; Rayeni et al., 2010). Coming down to South Africa, there is just about two papers so far, to our knowledge that have looked at efficiency of public universities, namely Taylor and Harris (2002) and Marire (2017). The shortcoming of these studies is that they are silent about changes in total factor productivity over time and they are pitched at an inter-university comparison level. We believe that better insights are generated from micro-analysis of each institution of higher learning given its unique institutional arrangements and culture that have a direct bearing on its performance.

Earlier thinkers, such as Baumol (1967), were of the view that the education sector was failing to benefit from technological change as well as from scale economies because it was technologically unresponsive, and it could not benefit from capital accumulation as well. He specifically argued that

inherent in the technological structure of [the education sector] are forces working almost unavoidably for 
progressive and cumulative increases in the real costs incurred in supplying [education]. Therefore, efforts to offset these cost increases, while they may succeed temporarily, in the long run are merely palliatives which can have no significant effect on the underlying trends (Baumol, 1967: 415).

The argument is that the education sector is labour intensive and does not allow for flexible substitution of labour and capital. However, it is evident that use of e-learning and online distance education suggests some level of capital-labour substitution or complementarity. In other non-educational sectors, technological change is critical for increasing productivity and reducing real costs of producing the same/higher level of output. Combined with capital accumulation and scale economies, technological change will always lead to falling real costs of production. In education, despite expansion of capital infrastructure and adoption of modern technology, costs of producing education have continued to rise and rise above the inflation rate globally. It seems to us that Baumol was concerned with the input mix effect and in any case he did not, as Levin, Jamison \& Radner (1976: 150) charge him, "see costs rising because of inefficiency; rather [he maintained] they are rising because of inevitability". Arjomandi, Salleh, \& Mohammadzadeh (2015: 630) concur that "universities usually operate at suboptimal scales", hence generally technically inefficient.

In this paper, we wish to partially address Baumol's claim which has almost become true. The empirical fact of rising costs of producing education is undeniable, but we want to analyse changes in productivity in higher education by decomposing them in ways that help us determine the role of technical change (innovation) in driving total factor productivity changes. With this approach we will also be able to analyse whether total factor productivity growth or decline has been driven by efficiency improvements or regressions. We use a case study of a small historically privileged South African university to do so. While we will not focus on the question of rising costs, we believe understanding sources/drivers of total factor productivity change is very crucial for strategy formulation for an institution of higher learning that is serious about financial sustainability (Rayeni et al., 2010). Strategies could range from increasing the size of the university, changing the output mix or generally improving efficient use of existing resources. Perhaps, such strategies can also attenuate 'forces working almost unavoidably for progressive and cumulative increases in the real costs incurred in supplying [education]'. Arjomandi et al. (2015), for example, give evidence to the effect that Malaysian public universities had major efficiency improvements after a national strategic planning intervention that focused on improving the utilisation of idle capacity.

The paper is organised as follows. Section 2 reviews literature on departmental efficiency and productivity change comparisons in universities. Section 3 discusses production theory and presents the method for measuring productivity changes over time. Section 4 discusses data sources. Section 5 presents the results and analysis. It also presents cluster analysis of the mean changes in total factor productivity and its efficiency components. This section is critical for institutional learning because it shows total factor productivity change leaders and followers and provides an incentive for institutional learning for inclusive total factor productivity growth. Section 6 concludes the paper and recommendations.

\section{Intra-university academic department efficiency and productivity change}

We briefly survey some work that has focused on academic departmental efficiency and productivity analysis. Most papers that have looked at departmental level analysis approached it from an efficiency point of view, but efficiency change is a sub-component of the change in total factor productivity and is a source of total factor productivity growth. Arjomandi et al. (2015: 632) concur with our argument, stating that "[f]ocusing mainly on efficiency estimates may lead to an incomplete view of the performance of universities over time". As such, much of the review here will be on papers focusing on efficiency and the few that have followed the total factor productivity change analytical strategy.

Rayeni et al. (2010) investigate changes in total factor productivity in academic departments of Islamic Azad University using a Malmquist Total Factor Productivity (TFP) Index under an input-oriented data envelopment analysis framework. The inputs used in the analysis were academic staff, student enrolment and number of guest lecturers. Outputs were taken to be research outputs, number of graduates and number of students progressing to higher level degrees. Their decomposition of the TFP changes revealed that the growth in total factor productivity was mainly driven by technical change. In addition, their results suggest that departments in the Faculty of Science experienced the strongest technical change and so, had the highest levels of total factor productivity growth. Their paper applied a similar approach to our analysis except that we utilise an output-oriented data envelopment approach over a much extended period unlike their two period analysis. We also applied cluster analysis to make more sense of the total factor productivity change patterns that we observed in our estimations, which they did not do. The input set they used was quite restrictive and potentially reduced the accuracy of the estimated total productivity index and its sub-components.

Kao \& Hung (2008) examined efficiency of academic departments of the National Cheng Kung University using both an input-oriented data envelopment analysis and cluster analysis approaches. Their study was a cross sectional study. They used total number of credit hours, publications and external grants as outputs. For inputs 
they used personnel in the departments, operating expenses and floor space. The focus on input-orientation was because they were more concerned with "efficiency of resource utilization rather than academic performance". Their findings established four major clusters of departments: [1] those that had higher teaching outputs because their courses served other departments, [2] those that had higher publications [3] those that attracted more external funding [4] those that could not be associated with any of [1] to [3] traits. Cluster [1] comprised languages departments, economics, accounting, mathematics, business administration and law. The second cluster [2] comprised engineering and medicine. The third cluster [3] comprised earth sciences, hydraulic engineering, aeronautical engineering, environmental engineering and manufacturing engineering. The conclusion was that the combination of low aggregate efficiency and low technical efficiency implied inefficient operations.

Moreno \& Tadepalli (2002) investigated efficiency of 42 academic departments in an anonymous public university. They used as outputs graduate majors, undergraduate majors, full time equivalents produced, student credit hours and grant awards. They also used faculty salaries, support stuff salaries, operational budget, capital budget and building space. Their findings revealed that sociology, anthropology, civil engineering, botany and veterinary sciences were the most efficient departments. As part of an effort to identify strategic areas that departments could exploit to eliminate inefficiencies, output and input slack analysis was used. Slack analysis identified areas of academic operations where a department could improve itself e.g. by expanding its enrolment or increasing its research outputs etc.

Beasley (1990) investigated the efficiency of chemistry and physics departments in the United Kingdom universities. Using general expenditure, capital expenditure and research income as inputs and number of undergraduates, number of taught postgraduates and number of research postgraduates as output, the paper found levels of efficiency to range between 0.44 and 1 . This paper went into details of discussing the implications of the findings on the shape and size of the university and stressed that the size of departments was crucial to their being efficient.

Arcelus \& Coleman (1997) estimated the departmental efficiencies for the University of Brunswick in Canada. Like many other studies, with some differences, they used teaching staff, support staff, operating budget and library budget as inputs and enrolment per class, sections taught, full time equivalent graduates, full time equivalent undergraduates, number of undergraduates graduating and number of graduates graduating as outputs. The major conclusion from this study was that a greater portion of inefficiency stemmed from the technical component of resource allocation patterns. They claimed that the input mix of the university departments played a crucial role in determining efficiency levels.

From the foregoing review, it can be observed that the comparison of academic departmental efficiency has been carried out on two fronts [1] focusing on the same discipline but using an inter-university comparative context (Beasley, 1990) [2] ignoring disciplinary orientation but using an intra-university comparative context (Arcelus \& Coleman, 1997; Kao \& Hung, 2008; Moreno \& Tadepalli, 2002; Rayeni et al., 2010). The problem with the first front is that it assumes that departments belonging to the same academic discipline tend to have a common production technology even if they are drawn from different universities. This assumption, realistic as it is, ignores the fact that the institutional environment and culture within a university have a critical contribution to how efficient departments become. For example, some universities are run on an entrepreneurial philosophy which entails paying incentives to academics for research done (Philpott, Dooley, O'Reilly, \& Lupton, 2011). Surely, such universities tend to have a high volume of publications. Quantity of publications and quality of publications are separate matters though. Similarly, some universities derive more income from private sources by enrolling larger numbers of students even if the infrastructural resources do not permit the massification process. This process is often accompanied by admission of more fee paying students relative to non-fee paying students.

The second front is important because it controls for uniformity of institutional environment and culture. Most studies, however, study efficiency at a point in time and not over time. We adopt the second front, which entails ignoring disciplinary orientation of departments but using an intra-university comparative context. The difference between our approach and the few papers that have followed an intra-university academic departmental efficiency comparison is that we compare changes in productivity for each department over a long panel period of 11 years. All studies we are aware of so far, except Rayeni et al. (2010), have evaluated departmental efficiency at a single point in time i.e. a particular year. Two things follow: [1] we are comparing the performance of a department against itself over time. Successive years are compared and overall period performance for that department is determined [2] we also compare each department to its peers on a year-on-year and over sample period bases. This yields a rich view of the evolution of efficiencies and productivity over time. This allows us to identify sources of productivity growth or decline, which can prove crucial to departmental and institutional strategy formulation.

The university we are studying is a small traditional university that was part of the English medium universities during the apartheid era. It was a historically privileged university just like any other formerly whitedominated university in South Africa. The university follows a liberal arts tradition. It is generally considered a research intensive university, but also is a teaching university. It has been in existence for over a century. It is one of the remaining universities that have withstood the modern trend towards commercialisation of the academy in 
South Africa. Our argument is that using such a "pristine" university which has not been tainted by the entrepreneurial drive helps us understand drivers of total factor productivity growth other than commercial motives.

This resistance to commercialisation has come at a price though, because often news breaks out that the university is not financially sustainable. For example, at the University's Institutional Transformation Summit in 2017, the University Council noted "several reasons for distorted cash flows, chief among [which] was the slow payment of student fees and higher than usual student debt ... [and] the University not achieving its enrolment targets". The university seems to have been in a transitional phase since 2007 , as it "has steadily shifted more focus onto research activities. This is evidenced by a greater increase in postgraduate student enrolments than undergraduate enrolments". The output mix has been altered and we suspect that this will be reflect in changes in scale efficiencies across departments. All in all, reports from the university suggest that for the period 2007 to 2016, "the university's financial health was relatively weak". Two issues stand out which commend themselves to the study of total factor productivity changes in this university: failure to meet enrolment target and alteration of research-teaching output mix. The first issue suggests the university is underutilising its scale of operation. The second issue suggests that the changing output composition might affect the scale of operation as well as financial sustainability, positively or negatively.

\section{Production theory and total factor productivity change measurement}

Every hierarchical economic structure (e.g. a university department) involved in production of services contends with the problem of limited means and unlimited ends. Such structures use inputs, which are transformed through a production function into outputs. Since a typical hierarchical structure is involved in production of multiple outputs using multiple inputs and does so over time, production theory provides a way of measuring productivity changes over time. In this paper we assume that a hierarchical structure (a university department in this case) seeks to maximise outputs, which in this case are teaching and research outputs, for a given level of inputs and production technology. This leads us to follow an output-oriented approach to measuring changes in total factor productivity. Total factor productivity is given by the ratio of total outputs to total inputs. The aggregation of the outputs and the inputs is executed through the index numbers approach. Our interest is not in the level of productivity but in the change in productivity over time. Production theory approaches this measurement using a Total Factor Productivity Index which allows us to measure the change in total factor productivity between any two data observations between consecutive time periods relative to a common production technology (Balk, 2013; Coelli, Rao, O'Donnell, \& Battese, 2005). The Malmquist index is a popular candidate. The Malmquist Total Factor productivity Index helps us measure progression or regression of efficiency and progression or regression of the production technology itself over time. This makes it a dynamic approach to analysing evolution of efficiency and productivity and the drivers of such changes which are obtained via decomposition of the Malmquist TFP index. To fix ideas, Figure 1 is a simplistic presentation of what production theory considers in evaluating productivity and efficiency changes. For simplicity of illustration, the graph is based on constant returns to scale, which entails that outputs increase by the same factor with which inputs have been increased.

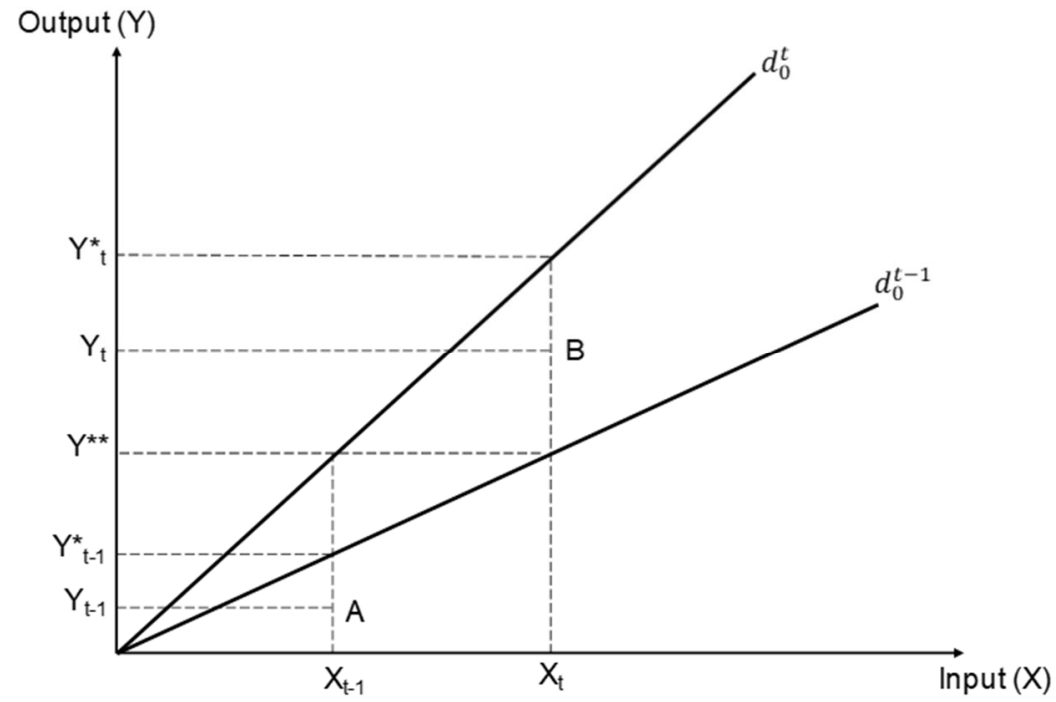

Figure 1: Output distance functions and measurement of productivity change

In Figure $1, d_{0}^{t-1}$ and $d_{0}^{t}$ are production functions/technologies of period $\mathrm{t}-1$ and $\mathrm{t}$ respectively. The decision making unit operates below its technological frontier in both time periods, at point A in period t-1 and B in period t. It is inefficient. Developments in the area of performance measurement have identified several sources of TFP growth. First, is technical change, which means that the production technology has shifted i.e. the set of maximal 
outputs or the production frontier has expanded or contracted (Coelli et al., 2005). In Figure 1 it is a movement from $d_{0}^{t-1}$ to $d_{0}^{t}$ or from $d_{0}^{t}$ to $d_{0}^{t-1}$. Technical change occurs because of innovation (Kaplan, 1999). An innovative organisation experiences cycles of technical change persistently (Jakovljevic, 2018).

Second, is technical efficiency change, which means the producer moves closer or retreats from the existing production frontier (Coelli et al., 2005). In Figure 1, this would be signified by moving from A towards $d_{0}^{t-1}$ in period t-1 and from $\mathrm{B}$ towards $d_{0}^{t}$ in period t.

Third, is scale efficiency change, which means that the producer has improved productivity by changing the scale of operations in such a way that a technologically optimal scale is attained (Balk, 2001). In Figure 1, this relates to the ability to produce the same/more output with fewer resources. For example, $\mathrm{Y}^{* *}$ can be produced on $d_{0}^{t}$ with input level Xt-1 which is less than Xt (an input level which could be used to produce it on $d_{0}^{t-1}$ ).

Fourth, is output mix effect, which means that a producer improves productivity by altering the combination of outputs (Balk, 2001; Coelli et al., 2005). This alteration of the output mix tends to influence scale efficiency. For example, a shift from postgraduate orientation to undergraduate orientation would undoubtedly influence scale change for an institution. This is because massification tends to have a greater effect on undergraduate studies than on postgraduate studies.

The conventional procedure is to combine these sources of productivity change to yield the Malmquist total factor productivity change (TFPC) (Coelli et al., 2005). The relationship can be stated as: $T F P C^{t-1, t}\left(\boldsymbol{X}_{t-1}, \boldsymbol{X}_{t}, \boldsymbol{Y}_{t-1}, \boldsymbol{Y}_{\boldsymbol{t}}\right)=$ technical change $*$ technical ef ficiency change $*$ scale efficiency change * output mix effect

$\mathrm{X}_{\mathrm{t}-1}$ is a vector of inputs used to produce a vector of outputs $\left(\mathrm{Y}_{\mathrm{t}-1}\right)$ in the previous period ( $\left.\mathrm{t}-1\right)$. $\mathrm{X}_{\mathrm{t}}$ is a vector of inputs used to produce a vector of outputs $\left(Y_{t}\right)$ in the current period $(t)$. Each of the components of Equation 1 is derived from an index. Each of the components of Equation 1 was estimated using decompositions of equation 2 to 5 .

The components of Eq.1 are formulated and estimated as follows.

technical change $=\left[\frac{d_{0}^{t}\left(\boldsymbol{X}_{t-1}, Y_{t-1}\right)}{d_{0}^{t-1}\left(\boldsymbol{X}_{t-1}, \boldsymbol{Y}_{t-1}\right)} * \frac{d_{0}^{t}\left(\boldsymbol{X}_{t}, \boldsymbol{Y}_{t}\right)}{d_{0}^{t-1}\left(\boldsymbol{X}_{t}, \boldsymbol{Y}_{t}\right)}\right]^{\frac{1}{2}}$

In Eq.2, $d_{0}^{t}$ and $d_{0}^{t-1}$ are production technologies (or frontiers) for period t and period $\mathrm{t}-1$ respectively, as we have them in Figure 1. Since productivity can either be measured relative to the previous period production technology or to the current period production technology, a geometric mean of the two measurements is used to generate a measure of technical change. The index in Eq. 2 states that technical change is a geometric mean of productivity growth in the previous period $(\mathrm{t}-1)$ and productivity growth in the current period $(\mathrm{t})$. The productivity change is measured by evaluating productivity in each period on the current production technology $\left(d_{0}^{t}\right)$ relative to the previous production technology $\left(d_{0}^{t-1}\right)$. In simple terms, Eq.2 states that if productivity evaluated on the current period production technology is different from productivity evaluated on the previous period production technology then we have technical change - the production function would have shifted inwards or outwards. If the technical change index is less than one, we have a problem of technical regression. If it is greater than one, it means there is technological progress. If the index is unity means the decision making unit has remained on the frontier as a best practice or benchmarking unit.

technical efficiency change $=\frac{d_{0}^{t}\left(X_{t}, Y_{t}\right)}{d_{0}^{t-1}\left(X_{t-1}, Y_{t-1}\right)}$

Eq.3 states that if productivity levels in the current period based on current technology is compared to previous period productivity based on previous period technology (see Figure 1) are different, we have technical efficiency change. This happens when the producer moves closer or further away from their production frontier e.g. moving from A towards/away from $d_{0}^{t-1}$ in period $\mathrm{t}-1$ and from $\mathrm{B}$ towards/away from $d_{0}^{t}$ in period $\mathrm{t}$ (Figure 1). This index can be greater than one (improvement in efficiency) or less than one (decline in efficiency) or equal to one (producer is on the frontier).

scale efficiency change $(S E C)=\left[\frac{S E C_{0}^{t-1}\left(X_{t}, Y_{t-1}\right)}{S E C_{0}^{t-1}\left(X_{t-1}, Y_{t-1}\right)} * \frac{S E C_{0}^{t}\left(X_{t}, Y_{t}\right)}{S E C_{0}^{t}\left(X_{t-1}, Y_{t}\right)}\right]^{\frac{1}{2}}$

Eq.4 states that scale efficiency change in the Malmquist approach of total factor productivity change analysis is a geometric mean of scale efficiency change with respect to previous period production technology and previous period output, and scale efficiency change with respect to current period production technology and current period output. Scale efficiency change can be greater than one, meaning the set of inputs used in production is closer to the technically optimal scale than the set of inputs used in the previous period. If the measure is equal to unity, it would mean that the current period production period experiences global constant returns to scale.

output mix effect $=\left[\frac{S E_{0}^{t-1}\left(\boldsymbol{X}_{t-1}, Y_{t}\right)}{S E_{0}^{t-1}\left(\boldsymbol{X}_{t-1}, Y_{t-1}\right)} * \frac{S E_{0}^{t}\left(\boldsymbol{X}_{t}, Y_{t}\right)}{S E_{0}^{t}\left(\boldsymbol{X}_{t}, Y_{t-1}\right)}\right]^{\frac{1}{2}}$

Eq. 5 states that the change in the output mix effect is a geometric mean of scale efficiency (SE) with respect 
to previous period production technology and scale efficiency with respect to current period production technology. The output mix effect is very complex to explain but in simple terms it measures the effect of a change in the composition of output on scale efficiency for the period under consideration. This measure can be one (an increase in output mix effect), less than one (a decline in output mix effect) or just one (no change in output mix). The paper employed decomposition represented in Eq. 1 to Eq. 5 to estimate changes in total factor productivity in academic departments of a small South African University.

\section{Method of analysis}

Before total factor productivity change decompositions are executed, a Malmquist data envelopment analysis (DEA) must be carried out to estimate efficiency scores. The DEA is a linear programming approach to measuring relative efficiency of relatively homogenous production units that utilise multiple inputs to produce multiple outputs. Departments of the same university would be regarded as relatively homogenous units. The basic approach is to construct an efficiency frontier or an envelope over all the data points in the sample and then calculate the distances of various data points to the envelope curve/frontier. Assuming that the decision making unit uses $\mathrm{W}$ inputs to produced $\mathrm{Z}$ outputs. Then the $\mathrm{i}^{\text {th }}$ input for decision making unit (DMU) $\mathrm{j}$ at time $\mathrm{t}$ is $X_{i j}^{t}$ and the $\mathrm{k}^{\text {th }}$ output for DMU $\mathrm{j}$ at time $\mathrm{t}$ is $Y_{k j}^{t}$. The Malmquist DEA program requires two same period measures and two different periods measures because the logic is to compare outputs produced under two different technological conditions in time.

The first same period measure of the output-oriented Malmquist DEA can be set up as follows:

$d_{0}^{t}\left(X_{0}^{t}, Y_{0}^{t}\right)=\min \theta$

Subject to:

$\sum_{j=1}^{n} X_{i j}^{t} \lambda_{j} \geq X_{i 0}^{t}, i=1,2,3, \ldots, W$

$\sum_{j=1}^{n} Y_{k j}^{t} \lambda_{j} \leq \theta Y_{k 0}^{t}, k=1,2,3, \ldots, Z$

$\lambda_{j} \geq 0, j=1,2,3, \ldots, n$

This linear programme is executed separately for each department and the subscript 0 refers to departments whose efficiency is being measured. The measure, $\theta$, lies between 0 and 1 inclusive and is a uniform scalar for reducing the outputs of a department $\left(\mathrm{DMU}_{0}\right)$. The minimum of $\theta$ is the efficiency score for the department $\left(\mathrm{DMU}_{0}\right)$ being evaluated. As the first equality in Eq.6 shows, the efficiency score is equal to the distance function of $\mathrm{DMU}_{0}$ at time $\mathrm{t}, d_{0}^{t}\left(X_{0}^{t}, Y_{0}^{t}\right)$. As such, if $\theta$ is unity, then $\mathrm{DMU}_{0}$ is regarded as efficient, which means its input-output combination lies on the frontier. Now, if $\theta<1$ the $\mathrm{DMU}_{0}$ is inefficient and is operating inside its frontier. The term $\lambda_{j}$ is a $1 \times 1$ vector of constants.

The second same period measure is formulated as follows:

$d_{0}^{t}\left(X_{0}^{t-1}, Y_{0}^{t-1}\right)=\min \theta$

Subject to:

$\sum_{j=1}^{n} X_{i j}^{t} \lambda_{j} \geq X_{i 0}^{t-1}, i=1,2,3, \ldots, W$

$\sum_{j=1}^{n} Y_{k j}^{t} \lambda_{j} \leq \theta Y_{k 0}^{t-1}, k=1,2,3, \ldots, Z$

$\lambda_{j} \geq 0, j=1,2,3, \ldots, n$

Notice that we are evaluating input-output combinations for current and previous period, $\mathrm{t}$ and $\mathrm{t}-1$, with respect to the same period production technology i.e. $d_{0}^{t}\left(X_{0}^{t-1}, Y_{0}^{t-1}\right)$ and $d_{0}^{t}\left(X_{0}^{t}, Y_{0}^{t}\right)$. The production technology is $d_{0}^{t}$. To have the different periods measure, we only need to similarly construct $d_{0}^{t-1}\left(X_{0}^{t}, Y_{0}^{t}\right)$, which means current period outputs are now being evaluated with respect to previous period production technology, $d_{0}^{t-1}$. The ultimate formulation from the two measures - same period and different periods - leads to the Malmquist Total Factor Productivity Change which is measured by Eq.1. A variable returns to scale output-oriented Malmquist DEA was estimated.

The data used in this paper was collected from publicly available Digest of Statistics from the University website. The digests of statistics were available for the years 2004 to 2015 . Data was collected for all departments except some that had lots of missing observations. A total of 33 departments were included in the study. Thus, the sample of the study was 12 years x 33 departments $=396$ observations. The data included six input variables and seven output variables. The inputs were student enrolments disaggregated by level of study (undergraduate, honours, masters and $\mathrm{PhD}$ ), capital expenditure and number of lecturers. Outputs were divided into teaching outputs and research outputs. Teaching outputs were three- and four-year undergraduate degree outputs, postgraduate diploma outputs, honours degree outputs and taught master's outputs. Research outputs comprised masters by research, doctoral research and publications. 


\section{Results and analysis}

5.1. Academic departments by their academic output orientations

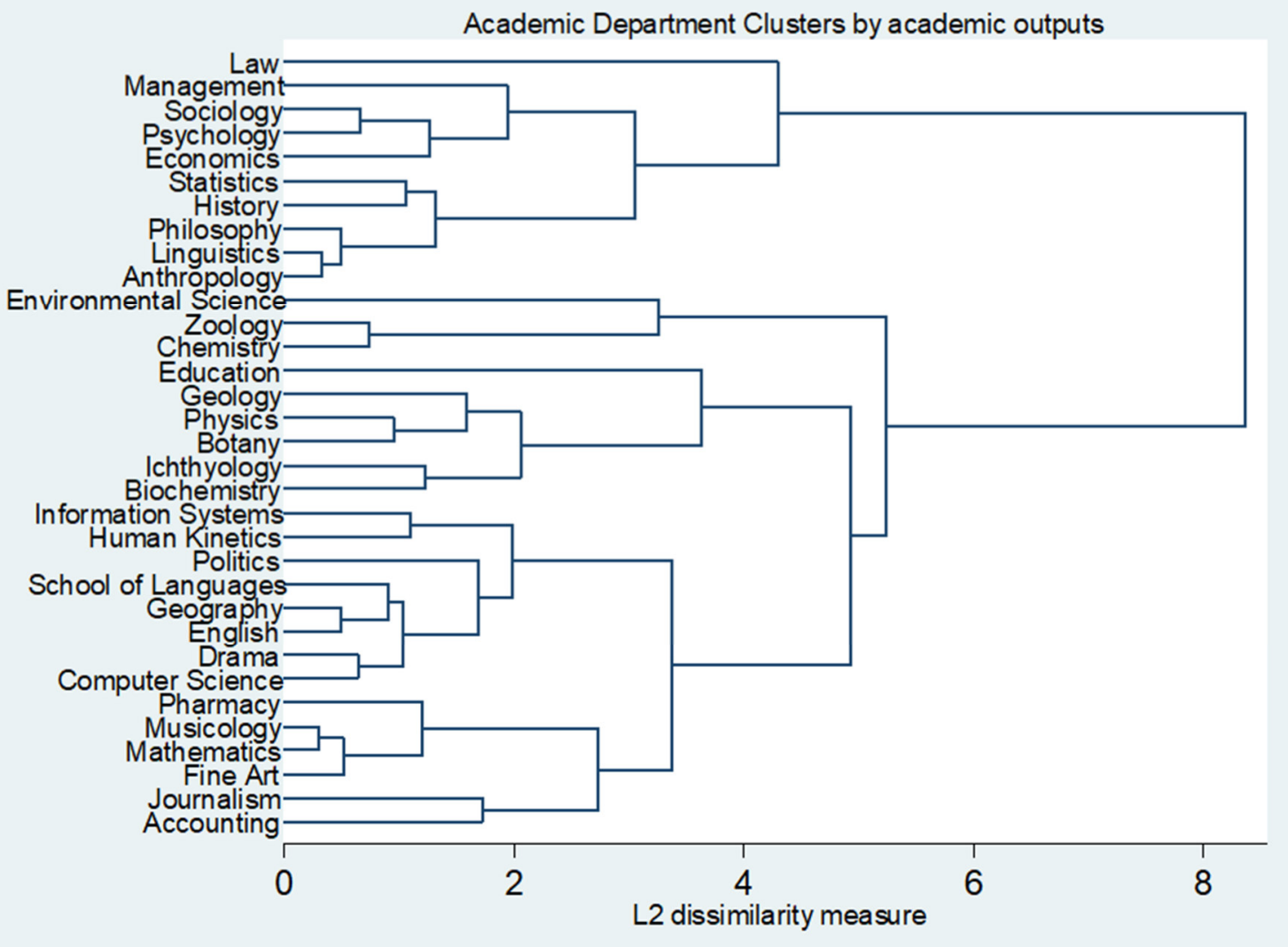

Figure 2: Departmental clusters by per capita academic outputs, 2004-2015

The dendrogram (Figure 2) has 4 broad clusters although these are overlapping. The clusters are: [1] the Teaching club e.g. Law, Management, Economics, Psychology, [2] the Research club e.g. Biochemistry, Botany, Physics, Chemistry, Zoology, [3] the Honours club e.g. Information Systems, Politics, Geography, English and [4] the Other teaching club e.g. Accounting, Journalism, Fine Art. These clusters are involved in production of every other output, but they are distinguished by the cluster label that we assigned them. In terms of outputs, the teaching club has very high outputs per lecturer as high as 8 undergraduates over 12 years. Law leads this group. The research club has very high publication and $\mathrm{PhD} /$ masters by research outputs. The average output is four publications per lecturer and $1.3 \mathrm{PhD}$ graduates per lecturer over 12 years. Chemistry leads this group. The honours club has, on average for the 12 years, produced 2.7 honours graduates per lecturer. However, there are members of the teaching club who have exceeded this honours club average e.g. Economics at 2.9 honours graduates per lecturer over the 12-year period. The other teaching club has Pharmacy which has a longer first degree qualification and accounting which has the Chartered Accountancy route plus various diplomas offerings. This group is led by Accounting at 3.7 3-\&4-year degree graduates per lecturer over the 12-year period. One could argue that these 12year period averages are lower than the latent potential of the university. For examples, it takes 3 years to complete a $\mathrm{PhD}$, so that in 12 years each lecturer, assuming they keep taking a new $\mathrm{PhD}$ candidate each successive year, would have to produce four PhD Graduates. Similarly, an honours degree is only a year's programme. If each lecturer had an honours student every year, one would expect each lecturer, in 12 years, to have produced 12 honours students. The point is that these averages suggest that there is so much unexploited productive capacity in the university. 
5.2. Total factor productivity change and its decomposition

Table 1: Eleven-year mean of total factor productivity change and its components for 2005-2015

\begin{tabular}{|c|c|c|c|c|c|c|}
\hline Faculty & Department & $\begin{array}{l}\text { Technical } \\
\text { efficiency } \\
\text { change }\end{array}$ & $\begin{array}{l}\text { Technical } \\
\text { change }\end{array}$ & $\begin{array}{l}\text { Pure } \\
\text { efficiency } \\
\text { change }\end{array}$ & $\begin{array}{l}\text { Scale } \\
\text { efficiency } \\
\text { change }\end{array}$ & $\begin{array}{l}\text { Total factor } \\
\text { productivity } \\
\text { change }\end{array}$ \\
\hline \multirow{4}{*}{ 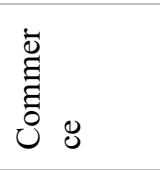 } & Accounting & 1.0321 & 2.9847 & 1.0000 & 1.0322 & 3.0094 \\
\hline & Economics & 1.0000 & 0.9720 & 1.0000 & 1.0000 & 0.9720 \\
\hline & Management & 1.0000 & 0.9902 & 1.0000 & 1.0000 & 0.9902 \\
\hline & Information Systems & 1.0000 & 0.8424 & 1.0000 & 1.0000 & 0.8424 \\
\hline Education & Education & 1.0000 & 0.9944 & 1.0000 & 1.0000 & 0.9944 \\
\hline Law & Law & 1.0000 & 0.8114 & 1.0000 & 1.0000 & 0.8114 \\
\hline \multirow{13}{*}{ 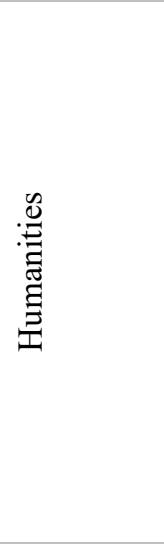 } & Anthropology & 1.0000 & 1.0183 & 1.0000 & 1.0000 & 1.0183 \\
\hline & Drama & 1.0000 & 0.9287 & 1.0000 & 1.0000 & 0.9287 \\
\hline & English & 1.0000 & 1.1050 & 1.0000 & 1.0000 & 1.1050 \\
\hline & English Language \& Linguistics & 1.0000 & 1.1373 & 1.0000 & 1.0000 & 1.1373 \\
\hline & Fine Art & 0.9899 & 0.8988 & 0.9842 & 1.0044 & 0.8794 \\
\hline & History & 0.9922 & 0.9998 & 1.0000 & 0.9922 & 1.0010 \\
\hline & Journalism \& Media Studies & 0.9881 & 0.9803 & 0.9925 & 0.9947 & 0.9702 \\
\hline & Music \& Musicology & 1.0030 & 0.8972 & 1.0000 & 1.0030 & 0.9049 \\
\hline & Philosophy & 1.0000 & 0.9287 & 1.0000 & 1.0000 & 0.9287 \\
\hline & Psychology & 1.0000 & 0.9479 & 1.0000 & 1.0000 & 0.9481 \\
\hline & Political \& International Studies & 1.0000 & 0.9608 & 1.0000 & 1.0000 & 0.9608 \\
\hline & School of Languages & 1.0000 & 0.9222 & 1.0000 & 1.0000 & 0.9222 \\
\hline & Sociology & 1.0016 & 1.1119 & 1.0010 & 1.0001 & 1.1127 \\
\hline Pharmacy & Pharmacy & 1.0350 & 1.1114 & 1.0135 & 1.0108 & 1.1029 \\
\hline \multirow{13}{*}{$\begin{array}{l}0 \\
\stackrel{0}{0} \\
\tilde{n}\end{array}$} & $\begin{array}{l}\text { Biochemistry, Microbiology \& } \\
\text { Biotechnology }\end{array}$ & 0.9997 & 1.0125 & 1.0000 & 0.9997 & 1.0137 \\
\hline & Botany & 1.0025 & 0.9799 & 1.0000 & 1.0025 & 0.9801 \\
\hline & Chemistry & 1.0000 & 1.1645 & 1.0000 & 1.0000 & 1.1645 \\
\hline & Computer Science & 0.9222 & 0.9305 & 0.9915 & 0.9895 & 0.9241 \\
\hline & Environmental Science & 1.0000 & 1.0075 & 1.0000 & 1.0000 & 1.0075 \\
\hline & Geography & 1.0000 & 0.7284 & 1.0000 & 1.0010 & 0.7333 \\
\hline & Geology & 1.0000 & 1.2005 & 1.0000 & 1.0000 & 1.2005 \\
\hline & Human Kinetics \& Ergonomics & 1.0004 & 0.9409 & 1.0000 & 1.0004 & 0.9450 \\
\hline & $\begin{array}{l}\text { Ichthyology \& Fisheries } \\
\text { Science }\end{array}$ & 1.0000 & 1.0176 & 1.0000 & 1.0000 & 1.0176 \\
\hline & Mathematics & 1.0082 & 0.8195 & 1.0000 & 1.0082 & 0.8607 \\
\hline & Physics & 1.0000 & 1.0633 & 1.0000 & 1.0000 & 1.0635 \\
\hline & Statistics & 1.0000 & 1.6190 & 1.0000 & 1.0000 & 1.6190 \\
\hline & Zoology \& Entomology & 1.0000 & 1.0380 & 1.0000 & 1.0000 & 1.0380 \\
\hline
\end{tabular}




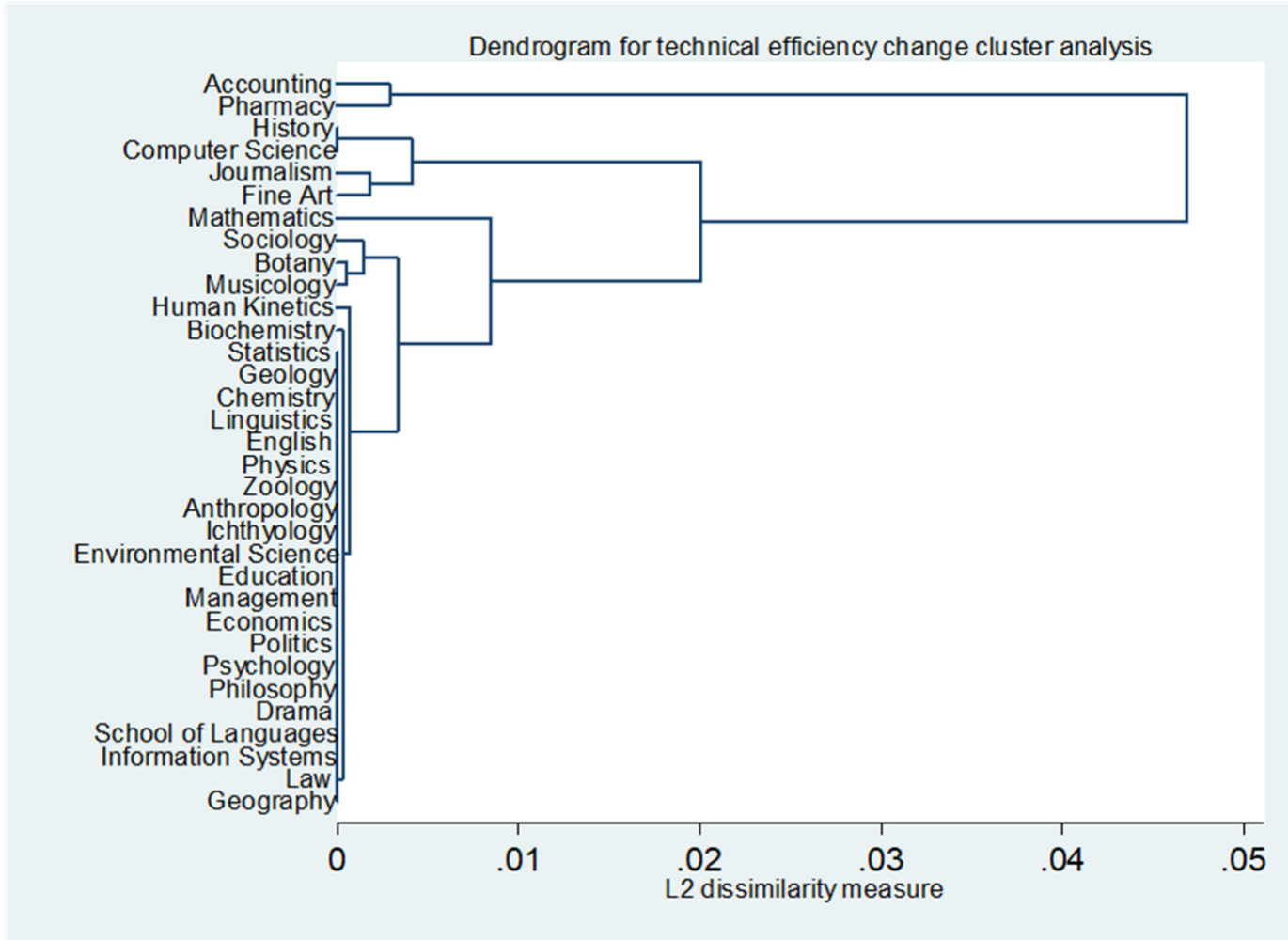

Figure 3: Dendrogram for mean technical efficiency change 2005-2015

The results from Table 1 and Figure 3 indicate that different departments have experienced changes in total factor productivity between 2004 and 2015 but the sources of the change were mixed. Firstly, $15 \%$ of the departments experienced a regression in technical efficiency. This means that they were operating inside their production frontiers. However, $64 \%$ of the departments remained on the frontier, i.e. remained best practice decision making units. For example, the largest regressions in technical efficiency were experienced by Journalism and Media Studies (1.2\%) and Fine Art (1\%). The largest progressions in technical efficiency were experienced by Mathematics $(0.8 \%)$, Accounting $(3.2 \%)$ and Pharmacy $(3.5 \%)$.

Secondly, $58 \%$ of the departments experienced an inward shift of their production functions (technical regression). The largest technical regression was experienced by Geography (27.2\%), Law (18.9\%) and Mathematics $(18.1 \%)$. The largest outward shifts in production functions were experienced by Accounting (198.5\%), Statistics (61.9\%), Geology (20.1\%), Chemistry (16.5\%) and English Language and Linguistics (13.7\%). This means that for the former group productive capacity declined, while for the latter group it increased significantly. There have been some innovation processes evolving in these decision making units. What those innovations are remains to be discovered by a more detailed analysis of these trends through interviewing decision makers.

Thirdly, $9 \%$ of the departments experienced a regression in resource allocative efficiency (pure efficiency regression), while $85 \%$ remained best practice decision making units in terms of resource allocation efficiency. This generally, indicates that resource allocation at the university seems to be largely optimal. Departments that experienced a regression in pure efficiency were Fine Art (1.6\%), Computer Science $(0.9 \%)$ and Journalism and Media Studies $(0.8 \%)$. Departments that had improvements in pure efficiency were Sociology $(0.1 \%)$ and Pharmacy $(1.4 \%)$. The rest remained on their frontiers.

Fourthly, $12 \%$ of the departments experienced a decline in scale efficiency, while $64 \%$ experienced global constant returns to scale for the entire period on average (meaning their inputs and outputs grew in equal proportions). Some of the departments that have experienced scale efficiency regression include Computer Science $(1.1 \%)$, History $(0.8 \%)$ and Journalism $(0.5 \%)$. This means they have not been operating at an optimal scale that their size entails. Departments that experienced progression in scale efficiency include Accounting (3.2\%), Pharmacy $(1.1 \%)$ and Mathematics $(0.8 \%)$. This means that they have improved utilisation of their latent scale capacity and their input levels are also set at optimally efficient scale.

Fifthly, $55 \%$ of the departments experienced a decline in total factor productivity. The largest growth in total factor productivity was experienced by Accounting $(201 \%)$, and most departments in the faculty of science $(0.8 \%$ to $61 \%)$, Sociology $(11.3 \%)$ and Pharmacy $(10.3 \%)$. Total factor productivity declined significantly in Geography (26.7\%), Law (18.9\%), Information Systems (15.8\%) and by small margins in Education (0.6\%), Management 
$(1 \%)$, Botany $(2 \%)$ and Economics $(2.8 \%)$. To gain further insight into the patterns emerging, cluster analysis is applied to Table 1 as the next section demonstrates.

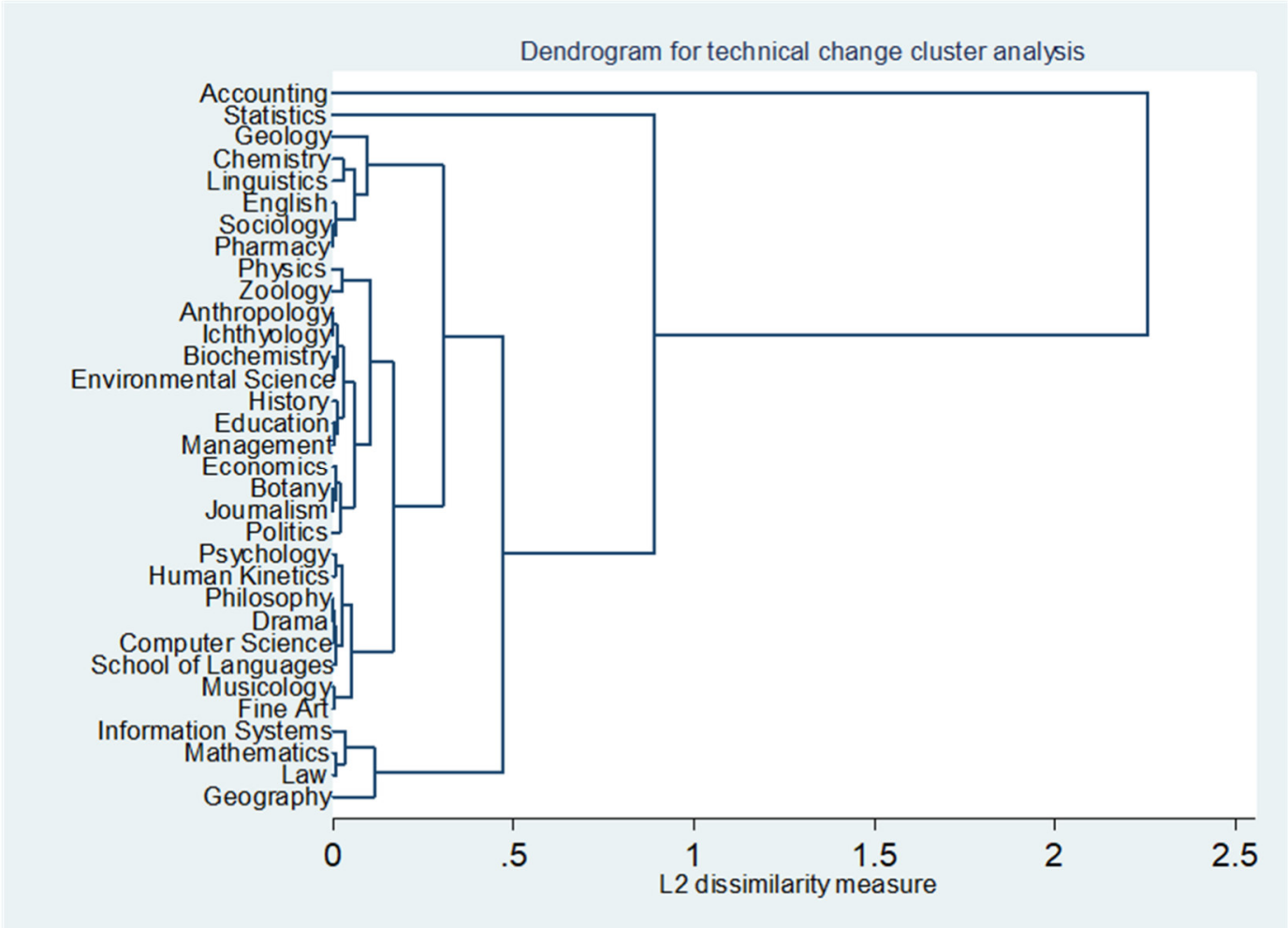

Figure 4: Dendrogram for mean technical change, 2005-2015

Figure 4 reveals several distinct clusters, with some overlapping. First, Accounting and Statistics stand out as departments that experienced very large outward shifts in their productive capacity, estimated at $198.5 \%$ and $61.9 \%$ respectively. This means that they can now produce much more output than they could in the past before such changes occurred. Second, there is a group of departments that experienced quite large outward shifts in their production frontiers by between $10.5 \%$ and $20.1 \%$ e.g. Geology, Chemistry, Sociology, English and Pharmacy. Third, is another group of departments that experienced modest outward shifts in their production frontiers by between 3.8\% and 6.3\% e.g. Physics and Zoology and Entomology. Fourth, there is a group that experienced marginal outward shifts in their production frontier by between $0.8 \%$ and $1.8 \%$ e.g. Anthropology, Ichthyology and Fisheries Science and Environmental Science. Fifth, We observe a group of departments that experienced marginal inward shifts in their production frontiers by between $0.02 \%$ and $0.98 \%$ e.g. Education and Management. Sixth, we observe a group of departments that experienced modest inward shifts in the production frontiers by between 1.97\% and 3.92\% e.g. Economics, Botany and Political and International Studies. Seventh, we also observe a group of departments that experienced above modest leftward shift in their production frontiers by between 2.01\% and 7.78\% e.g. Drama, Computer Science and Psychology. Eighth, Music and Musicology, and Fine Art stand alone, having experienced a leftward shift in their production frontier by $10.28 \%$ and $10.12 \%$ respectively. Ninth, three departments have quite large inward shifts in their production frontiers by between $15.76 \%$ and $18.86 \%$ e.g. Law, Mathematics and Information Systems. Lastly, Geography stands alone as the department that experienced the largest inward shift in its production frontier by about $27.2 \%$. 


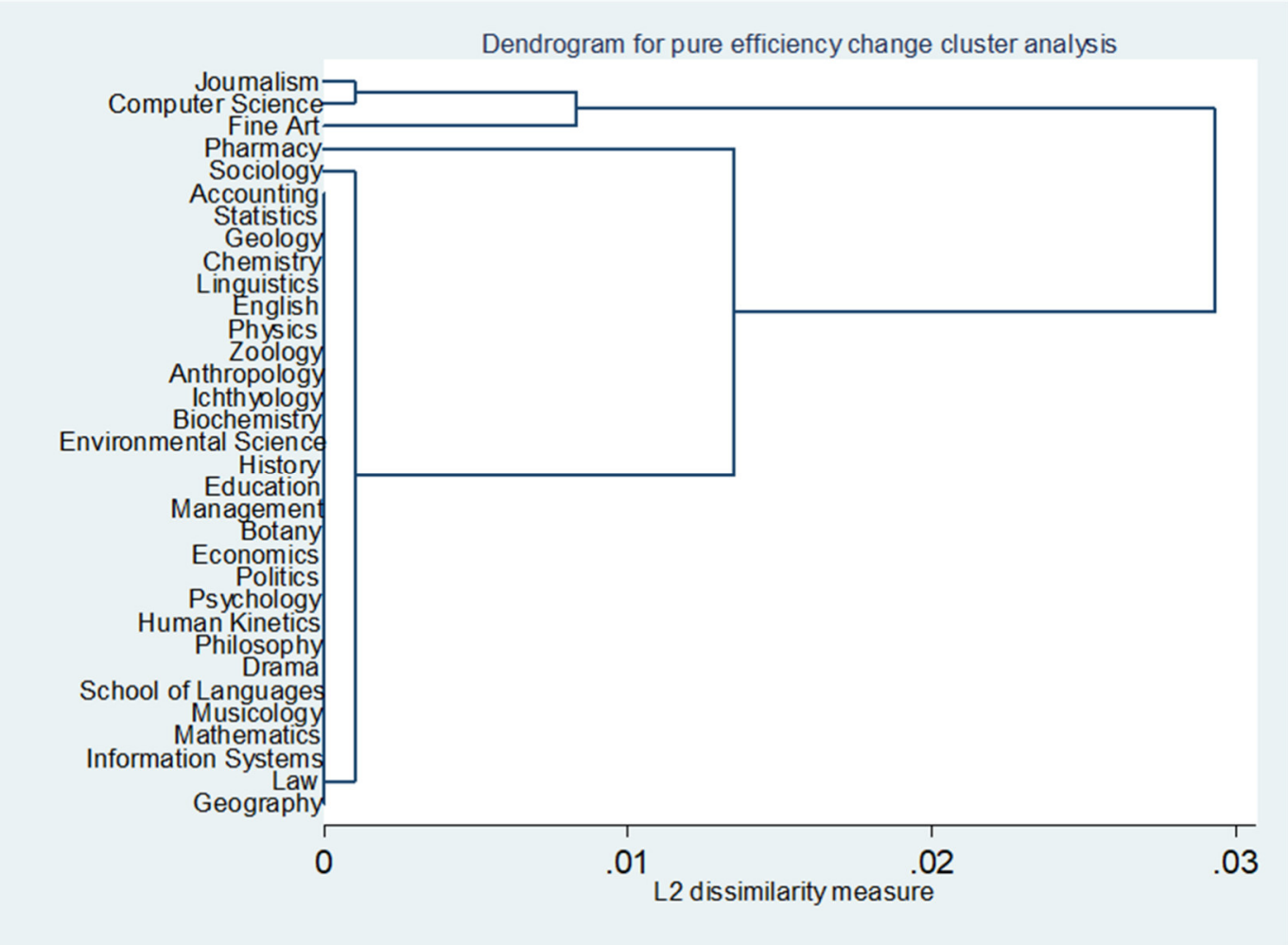

Figure 5: Dendrogram for mean pure efficiency change, 2005-2015

In Figure 5 there are three clusters. Journalism and Media Studies, Computer Science and Fine Art experienced a regression in pure technical efficiency by between $0.75 \%$ and $1.58 \%$. This means that resource allocation became sub-optimal. Only Pharmacy experienced an improvement in pure efficiency change by about $1.4 \%$. This means that the department moved closer to optimal levels of resource allocation. The remaining departments were best practice decision making units because they were allocatively efficient.

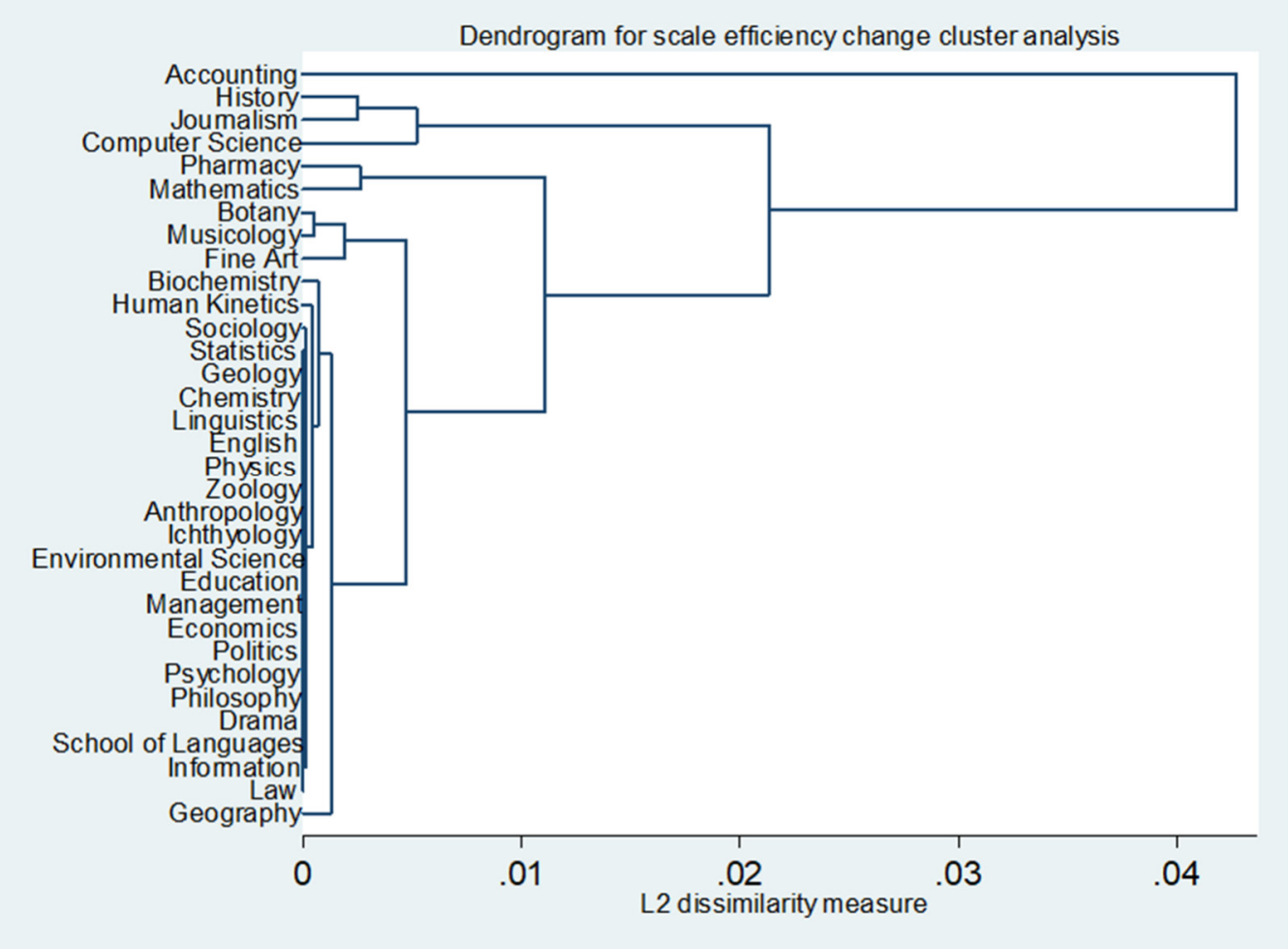

Figure 6: Dendrogram for mean scale efficiency change, 2005-2015

In Figure 6, six clusters are evident. Accounting stands alone as the department that experienced a large 
improvement in scale efficiency. Three other clusters experienced improvements in scale efficiency by $0.82 \%$ to $1.08 \%, 0.25 \%$ to $0.44 \%$ and $0.01 \%$ to $0.1 \%$. Examples from each cluster are Pharmacy and Mathematics, Botany and Fine Art, as well as Geography and Sociology respectively. Three departments experienced a decline in scale efficiency by between $0.53 \%$ and 1.05\%: Journalism and Media Studies, History and Computer Science. This means that they were not utilising their scale capacity optimally.

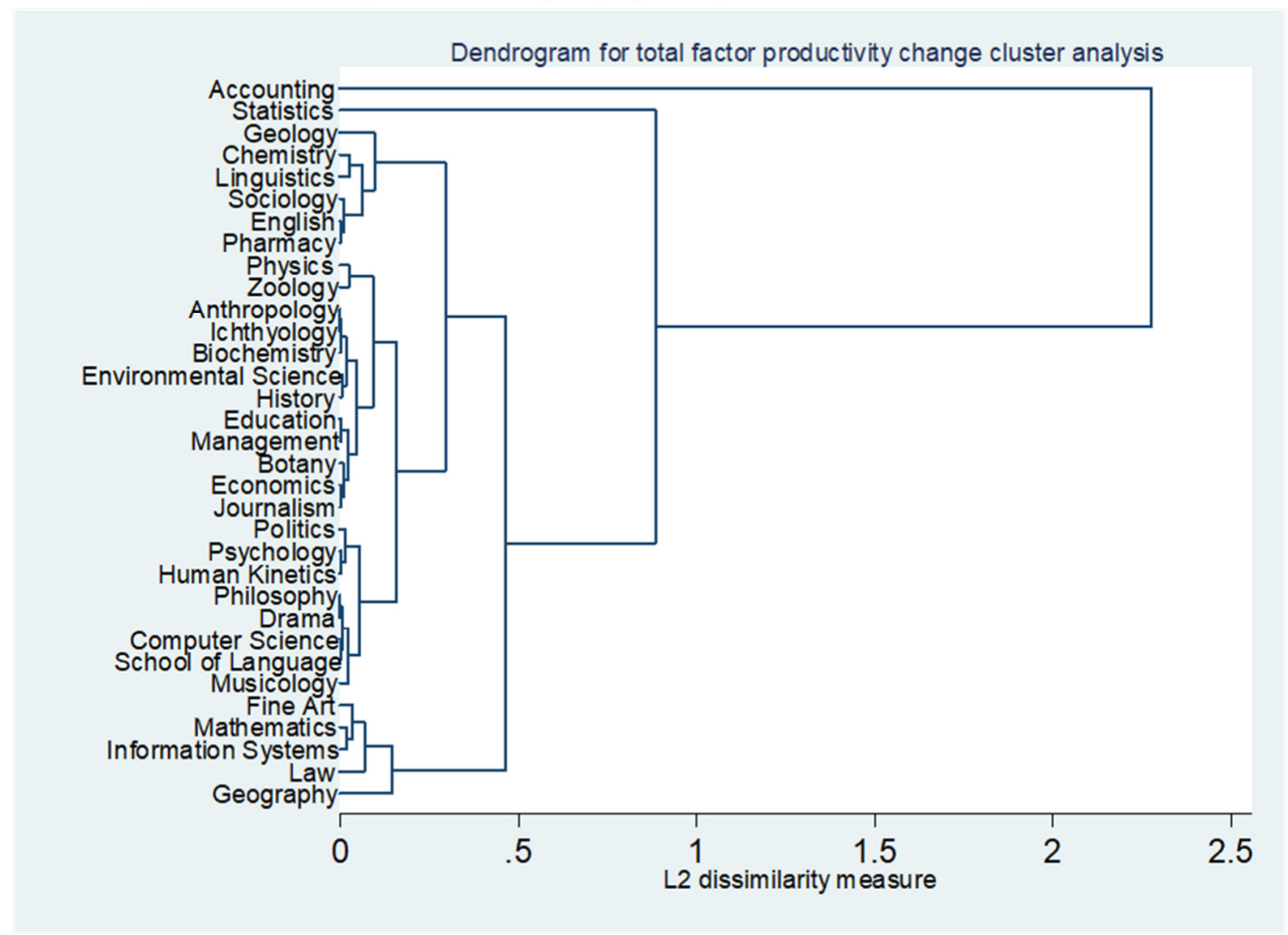

Figure 7: Dendrogram for mean total factor productivity change, 2005-2015

Figure 7 largely reflects the ten clusters which we observed in Figure 4. This probably, demonstrates that much of the change in total factor productivity was driven by technical change. Indeed, three departments experienced improvements in all four components of total factor productivity, with technical change been the dominating influence on total factor productivity growth. The departments are Accounting, Sociology, and Pharmacy. We observe that $27.3 \%$ of departments experienced only positive technical change i.e. an increase in productive capacity and another $27.3 \%$ experienced only negative technical change i.e. a decrease in the productive capacity. We also observe that two departments, Journalism and Media Studies, and Computer Science, experienced regressions in all four components of total factor productivity. The rest had mixed experiences: regressions and progressions in some components of total factor productivity change. It seems, however, that technical change dominated all other changes so that in most cases where it was a negative shock, it also filtered through to declining total factor productivity.

\section{Discussion and conclusions}

Baumol's view of inevitability of rising education costs seems not to be the case. The contradictory effects of regressions and progressions in efficiency components of total factor productivity explain the seeming inevitability. Inefficiency seems to be the underlying force that drives costs because total factor productivity rises at a slower rate than costs, which has the effect of increasing the marginal cost of providing education (Archibald \& Feldman, 2008; Levin et al., 1976; Sav, 2004). The solution is to improve productivity levels and our findings demonstrate how such sources can be identified and exploited to increase total factor productivity. Kao and Hung (2008: 654) point out that "efficiency decomposition helps the departmental head identify its weak areas for future improvement". The paper has demonstrated the value of analysing changes in total factor productivity within an institution. The value of this kind of work is largely managerial and for institutional learning purposes.

Firstly, given the reality of falling government funding for universities, it is incumbent upon individual higher education institutions to identify sources of output growth that they can optimise to improve their financial sustainability. 
Secondly, prudent institutional management will benefit from findings such as these by creating a vibrant institutional learning culture in which departments that are leading the growth in total factor productivity can share their strategies, practices and experiences with those that seem to lag. Various institutional forums can be sites for entrenching the institutional learning culture. The Deans' forum, the HoDs' forum and other institutional forums could potentially drive this agenda of facilitating real institutional learning.

The foregoing line of argument leads us to think about the possibility of designing an Institutional System of Innovation, at the heart of which will be the culture of intra-institutional learning. Universities are generally theorised as part of national or regional or local system of innovation because of their knowledge generation capabilities (Mazzucato \& Penna, 2015). Seldom, does literature think of universities as a system of innovation in their own right. A system of innovation is a governance arrangement in which different players - researchers, governors, managers, teachers, and departments interact to produce new products, create new productive processes as well as new arrangements that lower transaction costs of innovating (Albuquerque, Suzigan, Kruss, \& Lee, 2015; Jakovljevic, 2018; Lundvall, 2007). Technical change, by its nature, is a process driven by innovation and this speaks to the need for an institutional system of innovation (Kaplan, 1999). In a university innovation happens at many levels. In terms of products, it includes new degree offerings, new courses, new topics and new assessment mechanisms that speak to contemporary challenges. In short, curriculum changes are examples of both product and process innovations.

Our findings have their theoretical counterpart in the work of Jakovljevic (2018) who developed a model of innovation in higher education - Observation, Revelation, Exploration and Design (ORED). Their model sought to explain factors that influence an individual academic's innovativeness and inventiveness in higher education. The model encompassed institutional factors, individual factors and incentive systems that together create an ambition to innovate. Their model "is based on the foundations of a well-being society, institutional innovation, innovation culture, innovative personality frame, knowledge expertise, technologies, resources, and finally the innovation spirit that should be nurtured towards sustainable innovative outputs" (Jakovljevic, 2018: 122). This argument commends itself to the establishment of an institutional system of innovation. The argument they are putting forward is that the level of productivity of individual academics as measured by innovative outputs depends on several structural factors which include 'the business model of the university', 'institutional policies', 'incentive system', 'culture of communities of practice in innovation'. On evaluating South African universities, they find that "the lack of practical guiding steps, coordination and fragmented innovative actions of academics in South African ... are symptoms of inadequate social well-being, a lack of university innovative infrastructure and ineffective management" (Jakovljevic, 2018: 122-123). Their model identifies factors that are critical to a sustained innovation culture, not least have 'right policies', 'right infrastructure', 'right business model', 'sustained stimuli that encourage academic innovation', 'creation of multidisciplinary, interdisciplinary, pluri-disciplinary and transdisciplinary communities of practice in innovation', 'reforming teaching policies to bring teaching loads to their optimal levels so as to not stifle the innovative being in each academic', 'setting up incentive structures' and 'nurturing multiple collaborations and developing a new pedagogy of innovation'. In terms of our findings, what Jakovljevic's (2018) model entails is deeper waves of technical change that arise form cycles/waves of innovation. Total factor productivity, whether measured in terms of innovative outputs or any other academic outputs, is at its fundamental core an innovation-driven process. Thus, creating university institutional systems of innovation is an inevitable route to take if South African universities are not only going to financially sustainable but also increasingly impactful on societal problems.

The idea behind an institutional system of innovation is that the whole is greater than the sum of its parts and as such, exploitation of synergies and positive externalities arising from intra-institutional learning raises the level of total factor productivity exponentially (Cooke, Uranga, \& Etxebarria, 1997). Such a system involves institutional arrangements and incentive systems that foster productive interaction. Scholars who study the role of institutional learning and institutional change have demonstrated using a generalised social Darwinian theoretical framework that the process of institutional learning involves sharing social DNA (genes that promote social evolution) which is carried in genotypic structures such as practices, routines and strategies (Hodgson, 2003; Hodgson \& Knudsen, 2010; Ostrom, 2000). These genotypic structures do not exist in a vacuum. They exist in institutional systems such as departments (interactors) that interact in within the institution. The process of interaction leads to the diffusion of new ways of doing things, which should lead to a system wide technical change (Nelson \& Winter, 1982). The culture of institutional learning is probably the most important strategy that needs to be developed. Universities need to be learning institutions themselves in addition to them providing learning opportunities to communities and broader society. Dynamic institutions are identified by their ability to synergise individual departmental strengths in ways that result in a holistic dynamism across the institution.

Thirdly, given the centrality of technical change in fostering higher levels of total factor productivity coupled with the fact that government's funding formula is in fact couched in terms of total factor productivity, improving the productivity capacity of departments and the university as a whole becomes critical. Massification has become a common strategy among institutions to leverage on income streams, but we argue that institutions should learn 
to massify without dropping the ball on the qualify front. Increasing enrolments to fully utilise capacity where excess capacity exists is critical.

\section{References}

Albuquerque, E., Suzigan, W., Kruss, G., \& Lee, K. (2015). Developing national systems of innovation: University Industry interactions in the global south Edward Elgar Publishing.

Arcelus, F. J., \& Coleman, D. F. (1997). An efficiency review of university departments. International Journal of Systems Science, 28(7), 721-729.

Archibald, R. B., \& Feldman, D. H. (2008). Explaining increases in higher education costs. The Journal of Higher Education, 79(3), 268-295.

Arjomandi, A., Salleh, M. I., \& Mohammadzadeh, A. (2015). Measuring productivity change in higher education: An application of Hicks-Moorsteen total factor productivity index to Malaysian public universities. Journal of the Asia Pacific Economy, 20(4), 630-643.

Balk, B. M. (2001). Scale efficiency and productivity change. Journal of Productivity Analysis, 15(3), 159-183.

Balk, B. M. (2013). Industrial price, quantity, and productivity indices: The micro-economic theory and an application Springer Science \& Business Media.

Baum, S. (2016). Student debt: Rhetoric and realities of higher education financing Springer.

Baumol, W. J. (1967). Macroeconomics of unbalanced growth: The anatomy of urban crisis. The American Economic Review, , 415-426.

Beasley, J. E. (1990). Comparing university departments. Omega, 18(2), 171-183.

Bok, D. (2003). Academic values and the lure of profit. The Chronicle of Higher Education, 49(30), B7.

Calitz, E., \& Fourie, J. (2016). The historically high cost of tertiary education in south africa. Politikon, 43(1), $149-154$

Coelli, T. J., Rao, D. S. P., O'Donnell, C. J., \& Battese, G. E. (2005). An introduction to efficiency and productivity analysis Springer Science \& Business Media.

Cooke, P., Uranga, M. G., \& Etxebarria, G. (1997). Regional innovation systems: Institutional and organisational dimensions. Research Policy, 26(4), 475-491.

Dumestre, M. J. (2016). Financial sustainability in US higher education: Transformational strategy in troubled times Springer.

Hodgson, G. M. (2003). The mystery of the routine: The Darwinian Destiny of An Evolutionary Theory of Economic Change. Revue Économique, 54(2), 355-384.

Hodgson, G. M., \& Knudsen, T. (2010). Darwin's conjecture: The search for general principles of social and economic evolution University of Chicago Press.

Hong, W., \& Walsh, J. P. (2009). For money or glory? commercialization, competition, and secrecy in the entrepreneurial university. The Sociological Quarterly, 50(1), 145-171.

Hutchings, C., \& Garraway, J. (2010). Beyond the university gates: Provision of extended curriculum programmes in south africa. Rhodes University.

Jakovljevic, M. (2018). A model for innovation in higher education. South African Journal of Higher Education, $32(4), 109-131$.

Willmott, H. (2003). Commercialising higher education in the UK: The state, industry and peer review. Studies in Higher Education, 28(2), 129-141.

Kao, C., \& Hung, H. (2008). Efficiency analysis of university departments: An empirical study. Omega, 36(4), 653-664.

Kaplan, D. E. (1999). On the literature of the economics of technological change: Science and technology policy in south africa. South African Journal of Economics, 67(4), 255-262.

Levin, H. M., Jamison, D. T., \& Radner, R. (1976). Concepts of economic efficiency and educational production. Education as an industry (pp. 149-198) NBER. Available: http://www.nber.org/chapters/c4491 [Accessed 12 November 2017].

Lundvall, B. (2007). National innovation systems - analytical concept and development tool. Industry and Innovation, 14(1), 95-119.

Marire, J. (2017). Are south African public universities economically efficient? reflection amidst higher education crisis. South African Journal of Higher Education, 31(3), 116-137.

Mazzucato, M., \& Penna, C. (2015). Mission-oriented finance for innovation: New ideas for investment-led growth Policy Network and Rowman \& Littlefield International.

Mitchell, M., Leachman, M., \& Masterson, K. (2017). A lost decade in higher education funding state cuts have driven up tuition and reduced quality.

Mitchell, M., Palacios, V., \& Leachman, M. (2015). States are still funding higher education below pre-recession levels. Journal of Collective Bargaining in the Academy, O(Article 71). Available: htp://thekeep.eiu.edu/jcba/vol0/iss10/71. [Accessed 3 March 2017]. 
Moreno, A. A., \& Tadepalli, R. (2002). Assessing academic department efficiency at a public university. Managerial and Decision Economics, 23(7), 385-397.

Nelson Richard, R., \& Winter Sidney, G. (1982). An evolutionary theory of economic change. Harvard Business School Press, Cambridge,

Ostrom, E. (2000). Collective action and the evolution of social norms. The Journal of Economic Perspectives, 14(3), 137-158.

Philpott, K., Dooley, L., O'Reilly, C., \& Lupton, G. (2011). The entrepreneurial university: Examining the underlying academic tensions. Technovation, 31(4), 161-170.

Rayeni, M. M., Vardanyan, G., \& Saljooghi, F. H. (2010). The measurement of productivity growth in the academic departments using Malmquist productivity index. Journal of Applied Sciences, 10(22), 2875-2880.

Rhodes University (2004-2015) Statistical Digests. https://www.ru.ac.za

Sav, G. T. (2004). Higher education costs and scale and scope economies. Applied Economics, 36(6), 607-614.

Teixeira, P. (2009). Mass higher education and private institutions. Higher Education To, 2030, 231-258. 